\title{
A reivindicação do direito à saúde pelas Organizações Não Governamentais do Distrito Federal: garantia de direito social ou assistencialismo?
}

\author{
The "right to health" claim from the Federal District Non-Governmental Organizations: \\ enforcing social rights or paternalism? \\ ¿La reivindicación del derecho a la salud por las Organizaciones No Gubernamentales del \\ Distrito Federal: hacer cumplir los derechos sociales o paternalismo?
}

Regina Aparecida da Cruz ${ }^{1}$

RESUMO: Objetivo - Este artigo analisa a atuação das Organizações Não Governamentais (ONGs) na defesa da saúde no Distrito Federal (DF), a partir de um questionário respondido pelos seus dirigentes nos anos de 2008 e 2009. Metodologia Foi empregada a técnica da entrevista semiestruturada e análise do discurso do sujeito coletivo (ADS). Resultado: As ONGs têm atuado muito mais no assistencialismo primário, funcionando basicamente como prestadores de serviços aos usuários do sistema de saúde no DF do que como associações focadas em reivindicar a melhoria das políticas de saúde no DF em prol da garantia do direito social à saúde. Conclusão - A atuação das ONGs do DF tem sido insuficiente para influenciar politicamente a garantia do direito à saúde e, consequentemente, para atuar de forma condizente ao exercício da cidadania em saúde.

Palavras chave: Advocacia em Saúde. Organizações Não-Governamentais. Sistema Único de Saúde.

ABSTRACT: Objective - This article analyzes the advocacy initiatives of NGOs in enforcing health rights in the Federal District (DF) based on questionnaires answered by NGO leaders in 2008 and 2009. Methods - Both the semi-structured interview technique and the Discourse of the Collective Subject (ADS) were used. Result: NGOs have been more involved with primary health care, mainly acting as providers of services to users of the healthcare system in the Federal District, and not as associations focused on advocating in favor of improved health policies in the Federal District and guaranteeing the social right to health. Conclusion - The work of NGOs in the Federal District has been insufficient to politically influence the enforcement of the right to health and, consequently, to act in a manner consistent with the exercise of citizenship in health.

Keywords: Health Advocacy. Non-Governmental Organizations. Health Unify System

RESUMEN: Objetivo - En este artículo se analizan las acciones de las ONG en materia de defensa de los derechos de salud en el Distrito Federal (DF), basadas en cuestionarios respondidos por sus líderes en 2008 y 2009. . Metodología - Fue empleada la técnica de la entrevista semiestructurada y análisis del producto el discurso del sujeto colectivo (ADS). Resultado: Las ONG han estado más involucradas en la atención primaria de salud, actuando principalmente como proveedores de servicios a los usuarios del sistema de

\footnotetext{
${ }_{1}^{1}$ Advogada. Programa de Direito Sanitário da Fiocruz. Email: regina.cruz@gmail.com
} 
salud en el Distrito Federal, y no como asociaciones enfocadas en abogar por mejores políticas de salud en el Distrito Federal y garantizar el derecho social a salud. Conclusión - La actuación de las ONG del DF ha sido insuficiente para influir políticamente en la garantía del derecho a la salud y, consecuentemente, para actuar de forma acorde al ejercicio de la ciudadanía en salud.

Palabras Ilave: Defensa de la Salud. Organizaciones No Gubernamentales. Sistema único de Salud.

\title{
Introdução
}

A sociedade civil, como conceitua Cohen \& Arato em apud Ramos (1)

\begin{abstract}
é uma esfera de interação social entre a economia e o Estado, composta antes de tudo pela esfera íntima (em especial a família), a esfera das associações (em especial das associações voluntárias), os movimentos sociais e as formas de comunicação pública.
\end{abstract}

Portanto, a atuação da sociedade civil é de uma importância singular para pressionar o Estado na busca de se garantir que o direito à saúde se efetive. Neste sentido, Dallari (2) "não basta que o direito à saúde e suas garantias estejam expressos em documentos, é necessário torná-lo um direito garantido de fato". E, para esta garantia de fato, é fundamental que a sociedade civil participe da sua reivindicação e exercício.

O direito positivado é o início para a concretude de um direito, mas por si só não garante a sua efetivação. E quando se fala em saúde, um direito social como colocado na Constituição de 1988 (CF/88), há que se pensar em algo a mais, pois depende de políticas sociais e econômicas, como se observa da leitura do artigo 196 da CF/88.

A importância da participação da sociedade civil é enorme, pois é através das suas reivindicações que os direitos sociais podem ser impulsionados e concretizados pelo Estado, através da modificação de políticas existentes e de serviços disponíveis. Para que isso ocorra é preciso que a sociedade civil esteja, sobretudo, bem organizada para representar os cidadãos e da abrangência dessa representação, devendo-se considerar, também, a sua legitimidade. Como são organizações que nascem da vontade das pessoas, da necessidade de se buscar um direito preterido ou apenas esquecido. Elas são estruturadas e possuem força para representar todos aqueles que se encontram naquela condição de exclusão.

Um exemplo de como uma sociedade civil organizada pode trazer novas perspectivas para o grupo que representa, pode ser citado no caso das ONG de defesa dos portadores 
de HIV-AIDS ${ }^{2}$, que dentre outras conquistas em prol da garantia do direito à saúde de seus representados, conseguiram que o Banco Mundial concedesse um financiamento ao Brasil para controle da epidemia - o montante dos recursos e o fato de que o projeto foi a principal fonte de investimentos do país para controle da epidemia tornaram o empréstimo um ponto de inflexão na trajetória das políticas para a Aids, ensina Ramos (2004); e ela continua, outra conquista relevante aconteceu em 1996, com a concessão do acesso gratuito e universal, na rede pública da saúde, dos medicamentos anti-retrovirais (Lei 9.313 de novembro de 1996), graças aos reclamos judiciais protagonizados pela sociedade civil.

A sociedade civil, através dos movimentos sociais, tem um papel fundamental em organizar, articular, através do processo democrático veiculado na CF/88. Ela tem que se estruturar cumprir com o seu objetivo, promover as mudanças nas políticas de saúde de forma que garanta o direito à saúde. Elas devem atentar para uma nova proposta dessa participação social, e as ONGs no DF, que trabalham com o direito à saúde devem se organizar para garantir que as condições de reivindicar como, por exemplo, através da iniciativa popular produzir leis que defendem a saúde no DF.

Neste sentido, a pergunta de pesquisa que norteia o presente artigo é a seguinte: quais são as estratégias utilizadas pelas ONGs que defendem a saúde no DF para a garantia do direito à saúde e como elas estão estruturadas para realizar estas estratégias?

O objetivo geral do presente trabalho é verificar quais são as estratégias utilizadas pelas ONGs que defendem a saúde no DF, para aferir a sua capacidade de influir ou não nas políticas de saúde distritais para a garantia do direito social à saúde; encontram como objetivos específicos do presente trabalho temos: identificar as ONGs que trabalham com a saúde no DF, verificar as principais estratégias utilizadas pelas ONGs para a reivindicação do direito à saúde no DF, relacionar os resultados encontrados e discutir os resultados encontrados à luz da importância da atuação da sociedade organizada para garantir o direito à saúde.

Para construir a presente pesquisa partiu-se do mapeamento das ONGs que defendem a saúde no DF e a análise de entrevistas com os dirigentes dessas ONGs

\footnotetext{
2 Ensina Galvão (3), que as primeiras ONG dedicadas exclusivamente à Aids surgem depois 1985 e são: Gapa (1985, em São Paulo - Grupo de Apoio e Prevenção à Aids), esta por construir o primeiro serviço jurídico para pessoas portadoras de HIV-Aids, e por ter se tornado um modelo copiado por outras organizações, construiu o que mais tarde acabou sendo chamado de advocacy, Abia (1986, Associção Brasileira Inderdisciplinar de Aids) e Pela Vida (Em 1989, criada por Herbert Daniel).
} 
utilizando-se a metodologia de análise do discurso do sujeito coletivo (DSC). Estes dados encontram-se em poder da Fiocruz/Brasília, e foram levantados em pesquisa pretérita intitulada "Mapeamento dos Atores que Defendem o Direito à Saúde no Distrito Federal".

\section{Garantia do direito à saúde no brasil}

Os princípios jurídicos ${ }^{3}$ no ordenamento jurídico de um Estado, com razão se reconhece a importância dos princípios extraídos do texto constitucional, já que, por estarem no topo do ordenamento jurídico, influenciarão a formação, a interpretação e a integração de todas as demais normas, dando coerência e unidade de sentido a todo o sistema normativo. Os princípios constitucionais podem encontrar-se positivados ou não na Constituição e serão informadores da ordem política ou jurídica.

A Constituição é um conjunto de princípios que orientam a interpretação do ordenamento jurídico. E, consequentemente, o direito à saúde deve ser interpretado de acordo com a Constituição vigente, que delimita e orienta a atuação dos legisladores, dos administradores e dos operadores do direito.

Desta forma, toda e qualquer regra que incida sobre o direito à saúde, deve ser interpretada e aplicada conforme os princípios informadores. Valendo-se da hermenêutica constitucional $^{4}$, faz-se uma interpretação sistêmica, como ensina Silva (3).

A saúde no Brasil, antes da atual Constituição, era para poucos já que apenas os que se encontravam em atividade econômica formal tinham acesso à saúde. Os pobres em condição de miserabilidade sempre puderam contar com as Santas Casas, com a caridade. Mas os trabalhadores que se encontravam na informalidade só podiam acessar a saúde se pagassem para a iniciativa privada, Marques (4).

Como salienta Marques (4):

o sistema público de saúde brasileiro, até a promulgação da Constituição Federal de 1988, não merecia um tratamento constitucional específico e atendia somente aos indivíduos que contribuíssem à Previdência Social, ou seja, aqueles indivíduos que possuíssem carteira de trabalho assinada.

\footnotetext{
3 Os princípios são a base das normas jurídicas, influenciando sua formação, interpretação e integração e dando coerência ao sistema normativo. Eles podem impor obrigações legais (força normativa), orientaram o aplicador do Direito, possuem relevância jurídica e são mandamentos de otimização.

${ }^{4}$ Uma norma constitucional não pode ser considerada isoladamente, devendo sua interpretação levar em conta todo o texto constitucional.
} 
Com a vinda da $\mathrm{CF} / 88$ o direito à saúde ganha destaque no ordenamento jurídico brasileiro, passa a ser considerado direito fundamental, seguindo as diretrizes preconizadas pela Organização Mundial da Saúde (OMS).

Também merece destaque a condição político-social que antecede a chegada da $\mathrm{CF} / 88$. Como os constituintes queriam extirpar o processo ditatorial antecedente, eles trazem para a Assembléia Nacional Constituinte (ANC) um tratamento popular, participativo e democrático, sendo um dos motivos dela ser chamada de "Constituição Cidadã", conforme nos ensina Silva (3).

Neste diapasão o art. 196 da CF, prescreve

A saúde é direito de todos e dever do Estado, garantido mediante políticas sociais e econômicas que visem à redução do risco de doença e de outros agravos e ao acesso universal e igualitário às ações e serviços para sua promoção, proteção e recuperação.

A interpretação do art. 196 da CF tem sido há muito tempo objeto de estudo por parte da doutrina brasileira e faz parte também de diversos julgados pelo Poder Judiciário, face à necessidade de definir quem são os sujeitos passivos, efetivamente, dessa prestação.

A saúde não é apenas um direito social, mas também um direito que, como tem a sua origem no art. $6^{0}$ da CF, no Título dos Direitos Fundamentais, um direito de aplicação imediata, pois tem como cerne o direito à vida: o maior dos direitos do homem.

Neste sentido, o julgamento do SL 47-AgRPE ${ }^{5}$

A Constituição brasileira não só prevê expressamente a existência de direitos fundamentais sociais (artigo 60), especificando seu conteúdo e forma de prestação (artigos 196, $201,203,205,215,217$, entre outros), como não faz distinção entre os direitos e deveres individuais e coletivos (capítulo I e Título II) e os direitos sociais (capítulo II do Título II), ao estabelecer que os direitos e garantias fundamentais têm aplicação imediata (artigo 50, §10, CF/88). Vê-se, pois, que os direitos fundamentais sociais foram acolhidos pela Constituição

\footnotetext{
5 Trata-se de um julgamento, que aconteceu no STF, onde o ESTADO DE PERNAMBUCO requereu a suspensão da execução da liminar deferida na ação civil pública proposta pelo Ministério Público Federal e Estadual contra o MUNICÍPIO DE PETROLINA. A liminar foi deferida em desfavor do Município de PETROLINA para que este adotasse 8 (oito) providências administrativas para a melhoria imediata do atendimento no Hospital Dom Malan. Trata-se de um julgamento divisor de águas no STF quanto a possibilidade do Judiciário intervir nas questões orçamentários e de cunho discricionário do administrador.
} 
Federal de 1988 como autênticos direitos fundamentais. Não há dúvida - deixe-se claro - de que as demandas que buscam a efetivação de prestações de saúde devem ser resolvidas a partir da analise de nosso contexto constitucional e de suas peculiaridades.

A própria Constituição estabelece critérios para que seja bem compreendida a saúde no Estado Brasileiro, conforme preleciona Dallari (2)

\begin{abstract}
A Lei Maior da República estipulou critérios para que a saúde seja corretamente determinada em seu texto. Assim, vinculou sua realização às políticas sociais e econômicas e ao acesso às ações e serviços destinados, não só, à sua recuperação, mas também, à sua promoção e proteção. Em outras palavras, adotou-se o conceito que engloba tanto a ausência de doença, quanto o bem-estar, enquanto derivado das políticas públicas que ou têm por objetivo, seja apenas a política, seja sua implementação, traduzida na garantia de acesso - universal e igualitário - às ações e serviços com o mesmo objetivo.
\end{abstract}

O direito à saúde na CF/88 é um direito fundamental, garantido nos termos do art. 196 e seguintes da Carta Magna, conforme preleciona Dallari (2). Um direito que deve ser garantido pelas políticas sociais e econômicas, correspondendo a um dever essencial do Estado promover ações e serviços de saúde visando a construir uma nova ordem social.

Nesse mesmo condão, afirma Tojal (5), que a obrigação do Estado em relação às ações e serviços de saúde objetiva bem-estar e a justiça social e
com efeito, a garantia do direito à saúde, expressamente referida no artigo 196 da Constituição, inscreve-se exata e precisamente no rol daquele conjunto integrado de ações de iniciativa dos Poderes Públicos voltadas para a realização da nova ordem social, cujos objetivos são o bem-estar e a justiça sociais.

Está o Estado juridicamente obrigado a exercer as ações e serviços de saúde visando a construção da nova ordem social, cujos objetivos, são o bem-estar e a justiça sociais, pois a Constituição Ihe dirige impositivamente essas tarefas.

Não conceder à sociedade o direito de acesso à saúde é negar um Direito fundamental, é subtrair da coletividade tratamento digno garantido pela CF/88 e também em outros documentos internacionais como a Declaração Universal dos Direitos do 
Homem (DUDH) ${ }^{6}$, das Cartas $^{7}$ e da OMS. As Cartas consideram a saúde como um direito humano fundamental e essencial para o desenvolvimento pessoal, social e econômico.

Apreende-se da leitura do artigo XXV da DUDH, abaixo transcrito

Toda pessoa tem direito a um padrão de vida capaz de assegurar a si e a sua família saúde e bem-estar, inclusive alimentação, vestuário, habitação, cuidados médicos e os serviços sociais indispensáveis, e direito à segurança em caso de desemprego, doença, invalidez, viuvez, velhice ou outros casos de perda dos meios de subsistência fora de seu controle.

Neste sentido também Dallari (6), salienta que o direito à saúde se encontra inserida no rol dos Direitos Humanos e que a saúde foi inserida neste elenco mais recentemente.

Consolidando este entendimento Dallari (6), ensina

percebe-se, portanto, que ainda hoje a reivindicação por direitos humanos é arma dos oprimidos contra os opressores mas não se pode deixar de reconhecer que ela só é possível porque abriga uma idéia de direito fundamental, que independe do direito posto.

Seguindo esta linha de pensamento, a CF/88 trouxe um aparato legal que permite a construção de um estado democrático com uma extensa amplitude de direitos sociais e não apenas estes, mas também garantiu a participação direta e indireta dos cidadãos. Esta pode ser notada com muita clareza na presença dos partidos políticos e representação oriunda das organizações associativas de defesa de direitos, organizações sindicais, não governamentais, dentre outras elencadas no texto constitucional.

A CF/88 traz previsão no art. 198, III, da participação da sociedade como uma diretriz a ser adotada como mecanismo de fortalecimento do SUS

\footnotetext{
As ações e serviços públicos de saúde integram uma rede regionalizada e hierarquizada e constituem um sistema único, organizado de acordo com as seguintes diretrizes:

$[\ldots]$

III - participação da comunidade.
}

\footnotetext{
${ }^{6}$ A Declaração Universal dos Direitos Humanos (DUDH) foi aprovada em 1948 na Assembleia Geral da Organização das Nações Unidas (ONU). Este documento é a base da luta universal contra a opressão e a discriminação, defende a igualdade e a dignidade das pessoas e reconhece que os direitos humanos e as liberdades fundamentais devem ser aplicados a cada cidadão do planeta. (http://www.brasil.gov.br/sobre/cidadania/direitos-do-cidadao/declaracao-universaldos-direitos-humanos).

7 Conferencia de Alma-Ata, 1978; Ottawa, 1986; Adelaide, 1998; Sundsvall, 1991; Bogotá, 1992; Jacarta, 1997; Rede de Megapaíses, 1998; México, 2000; Bangkok, 2005.
} 
Garantir a saúde é dever do Estado e direito de todos, como elenca a CF/88 e este direito encontra-se além elencado também em vários outros documentos, inclusive internacionais. Para efetivar esta garantia a sociedade pode lançar mãos de institutos constitucionais importantes para a consolidação da democracia em nosso Estado, como a participação popular. A participação comunitária é fundamental para que seja o direito à saúde seja exercido.

\section{Saúde, movimentos sociais e cidadania}

A proposta da saúde, que integra o texto constitucional, foi construída em amplo processo democrático, com discussão e politização da questão da universalidade do direito à saúde, ocorrido nas décadas anteriores à CF/88.

A saúde no Brasil, a partir da década de 90, manteve o processo democrático através da participação da sociedade, pois os movimentos sociais que antecederam à Assembleia Nacional Constituinte foram muito significativos para perpetuar no tempo o um verdadeiro processo de discussão e politização da universalização deste direito, assim leciona Marques (7).

Os movimentos sociais participaram ativamente para construir um direito à saúde que respondesse à vontade, ao anseio da sociedade, por isso buscaram garantir que a prevenção fosse uma das áreas de cuidado do Estado. Neste sentido, Campilongo (8) prescreve

os movimentos sociais não possuem unidade de fins, coesão interna e uniformidade de ação. A unidade de um movimento social não decorre da essência de valores ou princípios (ainda que uma dimensão moral de luta do bem contra o mal sempre se faça presente). Ela resulta de um tema: a bandeira do movimento. Muitas vezes a percepção de uma carência. Geralmente, o sentimento de inacessibilidade a um direito.

Durante o período militar que foi de 1964 a 1985, a saúde foi fortemente negligenciada, e por óbvio, sem nenhuma participação popular. É neste cenário que nasce o Movimento Sanitário Brasileiro, datado do final da década de 70 - já no processo político de transição da ditadura para a democracia. Este movimento social de foi de relevância ímpar para a saúde, sendo que ele foi fortemente influenciado pela Revolução Sanitária Italiana, tendo como mentor Giovanni Berlinguer, ensina Dallari (6). Ele teve uma importante atuação para mudar os conceitos básicos de saúde que, resumia-se em 
assistencialismo e curativismo, para se garantir a saúde num conceito muito mais amplo, partindo da prevenção em nosso Estado, como ensina Marques (7) porque

a Reforma vai visar uma reconstrução da própria concepção de saúde, inserindo-a no contexto social brasileiro e uma reconstrução normativa e institucional dos serviços e ações de saúde no país. E, também, um novo olhar sobre o processo saúde-doença, sobre a elaboração e implementação das políticas de saúde, sobre as relações médicas, sobre a formação dos recursos humanos destinados ao trabalho na área da saúde, entre outros de forma mais próxima e articulada com a concepção de direito humano à saúde, à luz do disposto nos documentos internacionais.

O início deste movimento acontece no meio acadêmico, principalmente nos Departamentos de Medicina Preventiva, que zelam pela prevenção como valor maior para garantir a saúde. Também tem que destacar a importância do Centro Brasileiro de Estudos da Saúde (CEBES) e a Associação Brasileira de Pós-Graduação em Saúde Coletiva (ABRASCO) que foram importantes pilares para conseguir alcançar as conquistas alcançadas pelo Movimento, como se depreende da leitura de Marques (7).

O Programa de Montes Claros (MOC) ${ }^{8}$, segundo Escorel (9), foi um grande impulso para o processo de democratização e descentralização do setor da saúde. Este projeto tinha como princípio a participação popular que vinha reforçar as necessidades da comunidade, além de poder tornar uma realidade a prestação assistencial, onde as mudanças na vida social dessas pessoas - as excluídas de acessar a saúde - é que efetivamente se conquistaria tal garantia.

Mesmo antes da chegada do Sistema Único de Saúde (SUS) na CF/88, segue Escorel (9) este projeto já trazia os conceitos de regionalização, hierarquização, administração democrática e eficiente, integralidade da assistência à saúde, atendimento por auxiliares de saúde e participação popular.

A participação do movimento popular na saúde acabava por se tornar uma realidade (início da década de 80 ), porém ainda não havia uma legislação própria. Assim ensina

\footnotetext{
${ }^{8}$ Este projeto foi iniciado em 1974 por profissionais da área da saúde e desempenhou um papel histórico ao participar de ações e experiências de medicina comunitária, com recursos nacionais e internacionais. Eles levaram e implantaram na zona rural do município de Montes Claros a experiência, já bem sucedida em outros países e orientada pela OPAS, como a universalização do direito à saúde, integralidade e racionalização das ações, democratização popular, bem como experiências de atenção primária, já discutidas e preconizadas nas universidades como medidas necessárias ao acesso à saúde. Esse projeto era um avanço para Montes Claros, no que dizia respeito à política de atenção médica e de saúde discutida naquela época. Era um modelo global, regionalizado e hierarquizado de serviços de saúde, com participação popular.
} 
Marques (10), que durante a VIII Conferência de Saúde ${ }^{9}$ vê-se o fortalecimento dos movimentos sociais e inclusive a sua contribuição para a formulação das políticas públicas mais sistematizadas com a necessidade da participação da sociedade e a construção urgente de leis para proteção e o garantismo do direito à saúde ${ }^{10}$.

Neste sentido, prescrevem Costa e Sousa Júnior (11)

o movimento social pela reforma sanitária se configurou como um dos mais fortes protagonistas durante o processo constituinte que desaguou na Constituição de 1988 e teve, na $8^{\text {a }}$ Conferência Nacional de Saúde, realizada em Brasília, em 1980, um momento de definição de novas diretrizes para o sistema de saúde no Brasil.

A citada conferência efetivamente contribuiu para o atual sistema brasileiro de saúde, um sistema baseado na descentralização das ações e serviços de saúde, que conta com direção única em cada esfera de atuação do governo (municipal, estadual e federal), atendimento integral, priorizando a prevenção e também a ampliação da participação social, assim como o controle por parte da sociedade.

A necessidade de identificar carências sociais e oferecer alternativas que busquem a superação dos empecilhos de acessar o direito à saúde existentes, trazem um novo paradigma que é chamado de advocacia em saúde. Nesse condão Dallari (6) relata que "a advocacia em saúde desenvolve ações que procuram influenciar autoridades e particulares, sensibilizando-os para carências e necessidades sanitárias diversas".

Partindo da premissa de que as pessoas têm direitos fundamentais que são exigíveis por meio de procedimentos legislativos, administrativos ou judiciais, e, considerando que o direito à saúde se encontra positivado em nosso ordenamento jurídico, a advocacia em saúde é um processo de reivindicações de direitos que busca a implementação de uma política pública. Pode-se afirmar que se trata de garantir o acesso à saúde para todos os que foram contemplados pelo Estado legalmente, mas que se encontram excluídos.

Neste sentido ensina Dallari (6)

\footnotetext{
${ }^{9}$ Realizada de 17 a 21 de março de 1986, a conferência foi considerada a pré-constituinte, pelo então Presidente da República José Sarney. Houve a participação de mais de 4.000 pessoas oriundas dos mais diversos segmentos sociais e políticos. Desses participantes, mil eram delegados e, dentre estes, 50\% eram representantes da sociedade civil organizada.

10 Art. 4ํ- lei especial disporá sobre a garantia por parte da União ao direito à saúde, estruturando todos os órgãos públicos prestadores de serviços de saúde em sistema único, sob comando ministerial único, e mediante os seguintes postulados: [...] c) mecanismos de participação da sociedade organizada serão estabelecidos na formulação, controle da execução e da avaliação das políticas de saúde em todos os níveis do sistema.
} 
Como Estado Democrático de Direito, o Brasil tem na Constituição Federal os princípios e as normas que regem a democracia e a garantia dos direitos sociais, individuais, a liberdade, a segurança, o bem-estar, o desenvolvimento, a igualdade e a justiça. Portanto, a forma como o direito é declarado na lei afeta diretamente a atuação do advogado.

A advocacia em saúde (pode ter advogado profissional de saúde) difere-se da advocacia profissional. Aquela pode ter advogado, um profissional de saúde enquanto a segunda só pode ser um bacharel em direito e aprovado no exame aplicado pela Ordem dos Advogados do Brasil (OAB). Portanto, a primeira pode ser qualquer pessoa, ensina Dallari (1996), assim muito mais democrático e participativo. Um verdadeiro exercício da cidadania.

A Advocacia em Saúde baseia suas ações nos esforços organizados dos indivíduos e também de grupos, que têm como objetivo influenciar o governo, a administração pública, de modo que esses órgãos se tornem mais sensíveis às necessidades dos cidadãos, que garantam justiça social e acesso universal à saúde.

\section{Metodologia}

Foram analisados os documentos originários das degravações do conteúdo resultante das entrevistas"11 "Mapeamento dos Atores que Defendem o Direito à Saúde no Distrito Federal". Essas ONGs estão relacionadas com o garantismo do direito à saúde.

A metodologia do DSC foi escolhida por ser uma modalidade de análise dos discursos obtidos a partir dos depoimentos da manifestação discursiva que melhor se adequa aos objetivos traçados nesta pesquisa e justifica-se pelo fato de ser a mais adequada para se aferir os significados sociais.

Trata-se de uma mudança significativa nas pesquisas, pois permite que se conheçam os pensamentos, os valores, a crença dos seus atores sobre o tema debatido. Traz à pesquisa a manifestação direta do locutor, é a sua manifestação de expressão que se encontra no texto. Esse método se atém ao que foi colocado pelo entrevistado, pois é a presença do entrevistado na pesquisa, é a sua fala. Por isso ele é considerado fidedigno ao que pensa o entrevistado, é o que ensina Lefèvre e Lefèvre (12).

\footnotetext{
11 Entrevista aplicada aos dirigentes das ONG no DF, pelo CEPEDISA, nos anos de 2008 e 2009, às 12 (doze) ONG identificadas no território. As entrevistas estudadas contêm no máximo 30 (trinta) minutos e em torno de 9 (nove) perguntas.
} 
Neste sentido, Lefèvre e Lefèvre (12) explicam que, por este método

Se estará descrevendo muito melhor e mais adequadamente os pensamentos de indivíduos e coletividades quando estes estiverem sendo coletados, processados e apresentados sob a forma de discurso, porque os pensamentos pertencem à família das línguas e linguagens e, portanto, à ordem do discurso ou do texto.

O que se busca fazer com o DSC é "reconstruir, com pedaços do discurso individual, como em um quebra-cabeças, tantos discursos-síntese quantos se julgue necessário para expressar uma dada figura, ou seja, um dado pensar ou representação social sobre um fenômeno", ensina Lefèvre e Lefèvre (12).

Assim, será possível, através desta metodologia, encontrar o pensamento e as sustentações desses dirigentes acerca da seguinte questão, que norteou a pesquisa: quais as estratégias utilizadas pelas ONGs que defendem a saúde no DF para a garantia do direito à saúde e como elas estão estruturadas para realizar estas estratégias, identificando os discursos coletivos que se relacionam entre si e com o contexto político e social? E como preconiza Marques (10) dentro de cada grupo eles perseguem finalidades semelhantes e fazem parte do mesmo locus social. Desta forma, os fins almejados por uns são semelhantes ao dos outros. Há uma identidade entre eles.

Apesar do discurso ser redigido na primeira pessoa do singular, ele traz o pensamento coletivo, é o que afirma Lefèvre e Lefèvre (12)

\begin{abstract}
Mas a coletividade, falando na primeira pessoa do singular, não apenas ilustra o regime regular de funcionamento das representações sociais como também é um recurso para viabilizar as próprias representações sociais como fatos coletivos atinentes a coletividades qualitativas (de discursos) e quantitativas (de indivíduos). De fato, ninguém duvida que indivíduos compartilhem a(s) mesma(s) idéia(s), mas quando tais indivíduos opinam, individualmente, veiculam apenas uma parte do conteúdo da idéia compartilhada.
\end{abstract}

Acredita-se que com esta metodologia é possível aproximar a compreensão mais adequada da realidade do pensamento dos dirigentes das ONGs de como montam suas estratégias para garantir a defesa ao direito à saúde e de como podem melhorar a atuação da instituição na área da saúde. 
Após a escolha da pergunta ${ }^{12}$ que seria analisada, iniciou-se o processo de identificação dos principais argumentos elencados pelos entrevistados, a partir das suas falas. Estas falas permitiram uma visualização ampla do material e em seguida foi realizada a síntese dos discursos de cada um dos dirigentes dessas ONGs.

Assim, foi elaborada uma tabela com o agrupamento de expressões-chave e as respectivas idéias centrais e, também, uma tabela com as idéias centrais identificadas e o discurso coletivo proveniente de cada agrupamento de expressões chave.

Para se criar o DSC utiliza-se as seguintes figuras metodológicas, segundo Lefèvre e Lefèvre (12)

- Expressões-Chave: foram localizadas nos argumentos dos dirigentes das ONGs, as expressões que revelam a essência desses argumentos trazidos por cada um deles. Essas expressões são transcrições literais das entrevistas.

- Idéias centrais: são as expressões linguísticas que descrevem, da forma mais sintética e precisa possível, o sentido de cada expressão-chave (ou conjunto homogêneo de expressões-chave). Assim, a idéia central é uma descrição sintética do sentido dos argumentos encontrados.

Para a construção do DSC nesta pesquisa foram agrupadas todas as argumentações dos entrevistados. As argumentações de cada ONG continuaram a ser identificadas pelo número que recebeu na pesquisa (de 1 a 12). Passou-se, posteriormente, para a leitura detalhada de cada um desses argumentos, destacando-se os trechos considerados mais relevantes, que Ihes conferiam significância. Esses trechos relevantes foram destacados, separando-os dos demais pedaços do texto considerados irrelevantes para fins da presente análise. A identificação desses trechos mais relevantes possibilitou identificar as expressões-chave contidas nas argumentações dos entrevistados. As expressões-chave encontradas continuaram numeradas de acordo com o número do questionário.

O painel do DSC irá refletir o que um dado grupo ou em uma dada coletividade pensa sobre um determinado assunto. Tem-se como resultado desta pesquisa um painel de discursos que refletem como pensam e agem os dirigentes das ONGs acerca do exercício do direito à saúde.

\footnotetext{
12 Após estudar o material produzido na pesquisa, a partir da análise das entrevistas concedidas pelos dirigentes, que foram numeradas de 1 (um) a 12 (doze), foi selecionada uma pergunta do referido questionário, a saber: "que estratégias a instituição considera bem-sucedidas para a defesa da saúde? ".
} 


\section{Resultados}

A seguir, encontram-se as idéias centrais que compõem o DSC elaborado, a partir da questão abordada.

\section{Síntese de idéias centrais}

A - Diálogo e busca de atendimento digno à saúde junto aos representantes do Estado.

B - Articulação e manifestação pública junto aos demais movimentos sociais na área da saúde.

C - Participação nos Conselhos de Saúde.

D - Sensibilização na mídia e em veículos de comunicação técnico-científicos.

E - Cuidar dos doentes, informá-los e auxiliá-los dentro da própria associação.

F - Conscientização das pessoas em relação ao direito á saúde.

G - Fortalecer e defender o SUS como política pública de saúde.

H - Defender a aprovação de leis específicas para atender necessidades de saúde.

A partir da análise das ideais centrais, abaixo demonstrados no gráfico, apareceram as porcentagens nas entrevistas e chama a atenção o resultado obtido conforme análise apresentada logo a seguir.

Tabela 1: Ideias centrais dos dirigentes das ONGs.

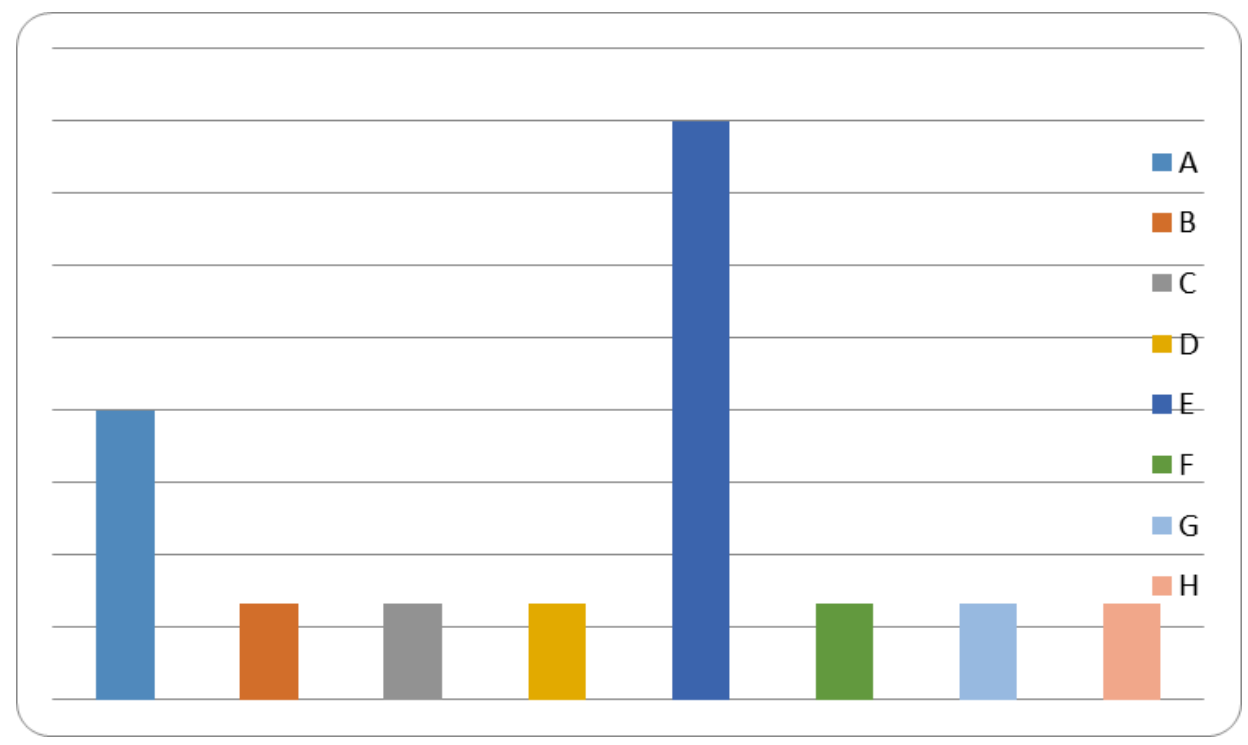

Fonte: Pesquisa realizada pelo Cepedisa ${ }^{13}$, nos anos de 2008 e 2009.

${ }^{13}$ Centro de Pesquisa e Ensino em Direito Sanitário. 
Chama a atenção a incidência das idéias A e E como idéias predominantes nos discursos dos dirigentes. E mais na primeira as ONGs colocam a necessidade de se ter no diálogo e na busca de atendimento digno à saúde junto aos representantes do Estado como a estratégia a ser considerada para serem bem-sucedidas na defesa da saúde. Já na segunda, resposta, a com maior incidência percentual, entende que as ONGs devem se dedicar a cuidar dos doentes, informá-los e auxiliá-los dentro da própria associação.

Percebe-se que as ONGs no DF, na sua maioria, estão atuando muito mais com base no assistencialismo do que como organizações que devem buscar garantir o acesso à saúde. Sendo que estas poderiam garantir a participação social, através do exercício da cidadania, realizando inclusão na democratização brasileira, assim como a base para a concretização das políticas sociais e também dos movimentos sociais garantindo o acesso à saúde.

Neste condão Dallari (6), ensina que "os brasileiros vivem simultaneamente duas experiências difíceis: aprender a democracia e aprender as formas de democracia contemporâneas". Talvez seja essa dificuldade dos brasileiros: conciliar o aprendizado com o exercício da democracia, colocar em prática a teoria.

Neste mesmo sentido Fleury (13) entende que

Uma cultura democrática combinaria unidade e diversidade, liberdade e integração. Enquanto a cidadania implica a unidade generalizante e a integração na totalidade, a construção do sujeito é uma afirmação da diversidade e da sua liberdade de criação. A cidadania implica a filiação a uma cultura, o compartimento de valores e normas, assim como a legitimação e subordinação ao poder estatal que afiança o universalismo dos direitos.

A necessidade de participação da comunidade nas ações e serviços públicos de saúde tem a sua diretriz ditada pela CF/88, como se observa da leitura do art. 198, III do referido texto legal. Esta orientação constitucional tem o condão de promover o exercício da cidadania e aperfeiçoamento da democracia em nosso país.

As ONGs são criadas para garantir que determinados direitos sejam garantidos, que determinados ideais sejam realizados. O assistencialismo que está sendo prestado remonta à primeira fase da evolução da saúde enquanto política moderna vivida até meados do século XIX, onde os mais pobres recebiam o atendimento de que necessitavam 
em conformidade com a caridade daqueles que a prestavam e não porque tinham o direito de ser tratados, atendidos. Neste sentido Foucault (14), ensina

$\mathrm{Na}$ figura do pobre necessitado que merece hospitalização, a doença era apenas um dos elementos em um conjunto que compreendia a enfermidade, a idade, a impossibilidade de encontrar trabalho, a ausência de cuidados.

As ONGs no DF vinculadas à saúde surgem no momento em que um determinado direito não está sendo cumprido, quando há uma transgressão de direitos, como advogadas em saúde - advocacy ${ }^{14}$ - das pessoas que não acessam a saúde. Elas vêm para garantir o acesso ao descumprimento de um direito fundamental: o direito à saúde. Neste entendimento Dallari (6) coloca que

as ONGs nascem quando algum direito é transgredido ou para firmar novos direitos, é da sua própria natureza desempenhar tal papel de modo permanente, uma vez que elas têm como finalidade melhorar as condições de vida intervindo em uma situação ou em uma política de saúde específica.

As ONGs no DF têm muito mais a fazer do que serem assistencialistas, para garantir o direito à saúde, como por exemplo, controlar a execução orçamentária, verificar se estão sendo gastos (aplicados) os 18,5\% (dezoito e meio por cento) do orçamento anual na saúde. Buscar a aprovação de leis junto ao Poder Legislativo, inclusive através de iniciativa popular ${ }^{15}$, participar das audiências públicas, tudo na busca da proteção do direito à saúde e outros que a CF/88 permitir. O que vem em consonância com outras respostas encontradas na pesquisa.

Atendendo este sentimento Dallari (6) ensina que

é extremamente necessária a atuação do advogado em saúde nos casos em que o recurso financeiro é condição para a implementação de uma política de saúde. O Poder Judiciário abre um novo espaço de atuação para o advogado em saúde, principalmente quando for uma ONG.

As ONGs podem se utilizar de instrumentos democráticos para efetivar o direito à saúde no DF, uma vez que a advocacia em saúde está em voga e bem aceita por doutrinadores como Dallari, Delduque, Marques, entre outros. Uma vez que estamos em

\footnotetext{
${ }^{14}$ Advocacia em saúde - tem sua origem no inglês - tem o significado de ações individuais e de grupos organizados que procuram influir sobre as autoridades e os partidos para que fiquem mais sensíveis às carências e necessidades diversas que emergem na sociedade.

${ }^{15}$ Art. $61, \S 2^{\circ}$ da CF
} 
um Estado de Direito e a participação social é uma das diretrizes adotadas constitucionalmente, tal instituto é fundamental para desenvolver políticas públicas eficientes e que tornem o direito à saúde uma realidade.

\section{Considerações finais}

No processo democrático em que vivemos, as ONGs têm um papel fundamental a percorrer para garantir o direito à saúde no DF. Para tanto elas devem partir para uma reivindicação coletiva, onde a união dos grupos reivindicantes seja fator de fortalecimento, de forma que se façam ouvir, no processo de negociação com os poderes públicos, que façam a diferença. Elas devem se impor como advocacy da coletividade e em nome de todos reivindicar o direito à saúde, pois o Estado é o responsável por garantir a saúde para todos.

É assim que se fará com que o direito que se encontra no papel (direito positivado) efetive-se, garantindo a todos o acesso à saúde, como direito fundamental que deve ser prestado pelo Estado de forma digna respeitando o que preconiza a CF/88 e os ordenamentos jurídicos internacionais de que somos signatários.

Dentro de um Estado de Direito, não se pode falar em participação popular sem legitimação. A advocacia em Saúde é o caminho eficaz para agilizar a legitimação dos princípios essencias elencados nas Cartas e Declarações e pela OMS, já que, como ela cuida de problemas específicos, acaba por dar sustentação à CF/88, no sentido de garantir a saúde. E por vez, promover o exercício da cidadania, trazendo a participação popular para definir a saúde que temos e a que queremos, participar da elaboração de políticas públicas na área da saúde em consonância com o que a coletividade precisa e quer.

\section{Referências}

1.Ramos, S. O papel das ONGs na construção de políticas de saúde: a Aids, a saúde da mulher e a saúde mental. Revista Ciência \& Saúde Coletiva. 9 (4): 1067-1078. 2004.

2. Dallari, SG. Uma nova disciplina: o direito sanitário. In: Revista Saúde Pública, São Paulo, 22 94): 327-334, 1988

3.Galvão, J. Aids no Brasil: a agenda de construção de uma epidemia. Rio de Janeiro: Editora 34, 2000. 
3. Silva, JA. Curso de direito constitucional positivo. São Paulo: Malheiros, 2011.

4.Marques, SB. O direito ao acesso universal a medicamentos no Brasil: diálogos entre direito, a política e a técnica médica. São Paulo: USP, 2011. Tese (Doutorado em Saúde Pública), Faculdade de Saúde Pública, Universidade de São Paulo, 2011.

6.Dallari, SG. Advocacia em saúde no Brasil contemporâneo. In: Revista Saúde Pública, São Paulo, 30 (6): 592-601,1996.

7.Marques, SB. O princípio constitucional da integralidade de assistência à saúde e o Projeto de Lei no 219/2007: interpretação e aplicabilidade pelo Poder Judiciário. In Revista de Direito Sanitário, São Paulo, 10: 64-86, 2009.

8.Campilongo, CF. Interpretação do direito e os movimentos sociais. Rio de Janeiro: Elsevier, 2012.

9.Escorel, S; Nascimento DR; Coelho FE. AS Origens da Reforma Sanitária do SUS. Saúde e Democracia História Perspectiva do SUS. Lima et al, (org), Cidade: Rio de Janeiro, Ed., Fiocruz, 2005.

10.Marques, SB. A relação do sistema jurídico e do sistema político na garantia do direito social à assistência farmacêutica: o caso do Estado de São Paulo. São Paulo: USP, 2005. Dissertação (Mestrado em Saúde Pública), Faculdade de Saúde Pública, Universidade de São Paulo, 2005.

11. Costa, AB e Sousa Junior, JG. O Direito Achado na Rua: uma ideia em movimento. In Costa el al,(org.), Brasília: Ed. CEAD/UnB, 2008.

12. Lefevre, F. Lefevre, AM. O sujeito coletivo que fala. Revista Interface, 10(20): 517-524, 2006

13. Fleury, S. Cidadania e Esfera Pública. In: Participação, Democracia e Saúde. Fleury,S (org.), Rio de Janeiro. 2009(Coleção Pensar em Saúde).

14. Foucault, M. A política de Saúde no Século XVIII. In: Microfísica do Poder. Rio de Janeiro: Ed. Graal, 2001 b.

5.Tojal, SBB et al. Constituição dirigente de 1988 e o direito a saúde. Os 10 anos da Constituição Federal. São Paulo: Atlas, 1998.

Recebido em: 5.6.2017

Aprovado em:24.7.2017

\section{Como citar este artigo:}

Cruz, RA. A reivindicação do direito à saúde pelas ONG do distrito federal: garantia de direito social ou assistencialismo? Revista Cadernos Ibero-Americanos de Direito Sanitário. 2017 jul./set, 6(3):30-47. 